\title{
TENTATIVAS DE INHIBICION DE LA SINTESIS DE ENTEROTOXINA ESTAFILOCÓCCICA POR PENICILINA Y ESTREPTOMICINA (1)
}

\begin{abstract}
Se realizaron tentativas de inhibir la producción de las enterotoxinas estafilocóccicas por las cepas ATCC 13565, ATCC 14458, $\mathbf{S}$ a y $\mathbf{S} 100$ con los antibióticos penicilina y estreptomicina. Los resultados obtenidos parecen demonstrar que la penicilina no impide la formación de proteinas enterotóxicas, siendo que por otro lado la estreptomicina a partir de la dosis de $500 \mu \mathrm{g}$ por ml de medio impide en casi todas las cepas la producción de enterotoxinas. Con la dosis de $1000 \mu \mathrm{g} / \mathrm{ml}$ no se pudo demonstrar presencia de enterotoxina en ninguno de los cultivos realizados con las diversas cepas. Se indican las posibles explicaciones para estos resultados.
\end{abstract}

\section{N T R O D U Ç A O}

Algumas cepas de Staphylococcus poseen la capacidad de sintetizar una toxina termo-resistente que al ser ingerida, provoca el aparecimiento de cuadros de intoxica. ción alimenticia. En algunas oportunidades se han descrito casos en los cuales la elaboración de esta enterotoxina se realizó en el tracto intestinal.

Los efectos de la terapéutica antibiótica sobre las infecciones producidas por estafilococos han sido ampliamente divulgados, conociendose también las transformaciones que sufren estos microorganismos al ser sometidos a la acción de estos agentes antibióticos (KLIENEBERGER-NoBEL ${ }^{13}, 1951$; Dienes \& Sharp ${ }^{6}$ 1956; MARSTON $\left.{ }^{14}, 1961\right)$.

Es también sabido que la zona de acción primaria de estos agentes antimicrobianos sobre las bacterias varia con los diversos antibióticos utilizados. Gene- ralmente se acepta que la penicilina inhibe la síntesis de la pared celular y la estreptomicina, a pesar de no presentar alteraciones en la pared celular, incrementa su permeabilidad e inhibe la síntesis de las proteínas citoplasmáticas.

Friedman \& White ${ }^{9}$ (1965) demonstraron a través de la técnica de inmuno. fluorescencia la presencia de enterotoxina estafilocóccica asociada a la superficie de la celula bacteriana.

Sabiendo que la enterotoxina es una proteína soluble en agua, rica en lisina y resistente a la acción de la tripsina, $\mathrm{H}_{\mathrm{AR}}$ MAN \& GOODGAL ${ }^{11}$ (1959) sugirieron que las enterotoxinas presentaban todas las características de los constituyentes de la superficie celular bacteriana. Habiendo tomano contacto con las alteraciones ocasionadas por algunos antibiótico sobre los estafilococos (Cotillo ${ }^{3}, 1962$ ) decidimos

Recebido para publicação em 27-10-1967.

(1) Da Cadeira de Microbiologia Aplicada da Faculdade de Higiene e Saúde Pública da USP.

(2) Da Cadeira de Microbiologia Aplicada da FHSP e da Cadeira de Microbiologia da Facultad de Farmacia y Bioquimica, Universidad Mayor de San Marcos, Lima, Perú. 
COTILlo z., L. G. - Tentativas da inhibición de la sintesis de enterotoxina estafilocóccica por penicilina y estreptomicina. Rev. Saúde públ., S. Paulo, 1(2):188-192, dez. 1967.

investigar la posibilidad de inhibir la producción de enterotoxina por antibióticos que impidiesen la biosíntesis de pared celular (penicilina) o de inhibidores de la síntesis de proteínas citoplasmáticas (estreptomicina) para, de alli, tratar de obtener mayores informaciones sobre el verdadero local de formación de la enterotoxina.

\section{MATERIAL Y MÉTODOS}

Cepas - Las cepas productoras de enterotoxina, usadas en la presente investigación fueron la 13565,14458 recibidas del ATCC y las cepas S 6 y S 100 gentilmente enviadas por el Prof Merlin S. Bergdoll, del Food Research Institute, University of Chicago. La cepa 13565 corresponde a la 196 E aislada por el Food Research Institute, University of Chicago, que produce la enterotoxina $A$. Esta cepa produce también gran cantidade de $B$ hemolisina que puede interferir en los ensayos biológicos. La cepa 14458 es la inicialmente denominada 243 aislada de materias fecales de niños, en Washington $y$ es productora de enterotoxina B. La cepa $S 6$ es formadora de enterotoxinas A y B y la $S 100$ sintetiza enterotoxina $A$.

Sueros - Los sueros hiperinmunes que sirvieron para demostrar la presencia de las enterotoxinas A y B fueron también gentilmente remitidos por el Prof. Merlin S. Bergdoll. Se usaron en la prueba de difusión en gel.

Producción de las enterotoxinas - Se siguieron los métodos recomendados por Casman \& BennetT ${ }^{2}$ (1963) y por HaLLANDER $^{10}$ (1965). El método dè Casman y Bennétt de produción de enterotoxina estafilocóccica A consiste en el uso de frascos de Roux conteniendo $100 \mathrm{ml}$ de "Bacto-Brain Heart Infusion", colocando, dentro de los Roux, bolsas de celofán y dentro de éstas $0,5 \mathrm{ml}$ de la suspensión estafilocóccica preparada a partir de un cultivo en agar inclinado de 18 a 24 horas, debiendo contener la suspensión aproxi- madamente 300 millones de microorganismos por ml.

El inóculo se distribuye sobre la superficie interna del celofán, en contacto con el medio de cultivo y a seguir, se infla el saco de celofán y se coloca la botella de Roux en posición inclinada, cuidadosamente. La incubación es realizada por 72 horas a $35-37^{\circ} \mathrm{C}$. El cultivo del saco de celofán es extraído con una pipeta de $\mathrm{I} \mathrm{ml}$, adicionando $0,5 \mathrm{ml}$ de salina a $0,85 \%$ esteril

Para evitar la diluición de la enterotoxina producida el volumen final no debe ser mayor de $1 \mathrm{ml}$. Los estafilococos son eliminados por centrifugación a $2.500-$ 3.000 RPM y el sobrenadante, conteniendo la enterotoxina, es separado y guardado en la refrigeradora entre $4^{\circ}-6^{\circ} \mathrm{C}$.

El método de Hallander indicado para la producción de grandes cantidades de enterotoxina B y otras toxinas estafilocóccicas en medio sólido, utiliza el medio descrito por CASMaN ${ }^{1}$ (1958) modificado por Bergdoll con la adición de $2 \%$ de hidrolizado de proteína en placa de Petri de $14 \mathrm{cms}$ de diámetro, con la superficie del medio cubierto por celofán e incubando por 24 horas a $37^{\circ} \mathrm{C}$. La inoculación se hace con $5 \mathrm{ml}$ de una suspensión bacte. riana en tampón de fosfato con una densidad de 0,6 de coeficiente de extinción medido en colorímetro Beckman Mod. C con filtro verde.

Determinación de la presencia de enterotoxinas - Se han descrito numerosos métodos para la identificación de la enterotoxina estafilocóccica, DACK et alii ${ }^{5}$ (1930) utilizan voluntarios humanos. Dolman et alii ${ }^{7}$ (1936) proponen el em. pleo de gatitos jovenes, método posteriormente perfeccionado por HAMMON ${ }^{12}$ (1941). Otros investigadores describen el uso de macacos rhesus (Macaca mu. latta) asi como de arañas.

Muchos otros animales se han usado en las tentativas de conseguir un médio mas fácil, mas rápido y mas seguro para 
COTILlo z., L. G. - Tentativas da inhibición de la síntesis de enterotoxina estafilocóccica por penicllina y estreptomicina. Rev. Saúde públ., S. Paulo, 1(2):188-192, dez. 1967.

evidenciar la enterotoxina estafilocóccica. Entre estos podemos mencionar sapos, ratones blancos, ratones silvestres, ratas cobayas, conejos, perritos, canarios y lechones.

Sin embargo, el uso de animales siempre trae consigo el problema de la interferencia de las reacciones biológicas propias de cada individuo con las ocasionadas por el agente que se esta probando.

Es por eso que, continuando con la búsqueda de un mejor método para esta finalidad, Casman ${ }^{1}$ (1958) describe una técnica de difusión en gel para la identificación serológica de las enterotoxinas, que simplifica los métodos de laboratorio hasta entonces utilizados y que permite diferenciar las diversas enterotoxinas hasta hoy reconocidas

Asi, la determinación serológica de la presencia de enterotoxina producidas por las cepas de estafilococo en el presente estudio se hizo a través de la reacción de Wadsworth, modificada por CROWLE ${ }^{4}$ (1958), conforme descripción de CASMaN ${ }^{1}$ (1958). La confirmación biológica se hizo inoculando el material en estudio en gatos pequeños por vía intravenosa segun el método descrito por Hammon. Se tuvo cuidado de no emplear gatos mayores de tres meses.

Inhibición de la sintesis de enterotoxinas - Con la finalidad de conseguir la inhibición de la síntesis de enterotoxinas se adicionó a los medios utilizados para la producción de estas toxinas, penicilina a las concentraciones de $100 \mathrm{U}, 200 \mathrm{U}$, $400 \mathrm{U}, 600 \mathrm{U}$ y $800 \mathrm{U}$ por ml de medio. La estreptomicina fué utilizada a las concentraciones de $10 \mu \mathrm{g}, 50 \mu \mathrm{g}, 100 \mu \mathrm{g}$, $500 \mu \mathrm{g}, 1000 \mu \mathrm{g}, 2000 \mu \mathrm{g}$ y $4000 \mu \mathrm{g}$ por ml de medio de cultivo.

\section{RESULTADOS}

En la fase inicial de este trabajo, con la finalidad de obtener buenas cantidades de enterotoxinas se comparó las técnicas recomendadas por CASMAN \& BENNETT ${ }^{2}$ (1963) y por Hallander ${ }^{10}$ (1965). Para la demonstración de la inhibición de la síntesis de enterotoxinas se prefirió usar el método de los sacos de celofán de Cas. man y Bennett, adicionando al medio la cantidad requerida de penicilina o estreptomicina. $\quad \mathbf{L a}$ inculación fué siempre realizada a la temperatura de $37^{\circ} \mathrm{C}$ por 48 y 72 horas sin agitación.

La concordancia entre las técnicas serológica y biológica (ésta realizada en gatos) fué total.

En la Tabla 1 presentamos los resultados obtenidos en la tentativa de inhibir la sintesis de enterotoxinas estafilocóccicas empleando penicilina.

TABLA 1

Inhibición de la sintesis de enterotoxinas estafilocóccicas por la penicilina

\begin{tabular}{|c|c|c|c|c|c|c|c|c|c|}
\hline \multirow{2}{*}{$\begin{array}{l}\text { Concentracio- } \\
\text { nes de pent- } \\
\text { cilina }\end{array}$} & \multirow{2}{*}{\begin{tabular}{|} 
Cepas \\
tiempo de \\
incubación
\end{tabular}} & \multicolumn{2}{|c|}{ ATCC 13565} & \multicolumn{2}{|c|}{ ATCC 14458} & \multicolumn{2}{|c|}{ S 6} & \multicolumn{2}{|c|}{ S 100} \\
\hline & & $48 \mathrm{~h}$ & $72 \mathrm{~h}$ & $48 \mathrm{~h}$ & $72 \mathrm{~h}$ & $48 h$ & $72 \mathrm{~h}$ & $48 \mathrm{~h}$ & $72 \mathrm{~h}$ \\
\hline $100 \mathrm{U} / \mathrm{ml}$ & & + & + & + & + & + & + & + & + \\
\hline $200 \mathrm{U} / \mathrm{ml}$ & & + & + & + & + & + & + & + & + \\
\hline $400 \mathrm{U} / \mathrm{ml}$ & & + & + & + & + & + & + & + & + \\
\hline $600 \mathrm{U} / \mathrm{ml}$ & & + & + & + & + & $t$ & + & + & + \\
\hline $800 \mathrm{U} / \mathrm{ml}$ & & + & + & + & + & + & + & + & + \\
\hline
\end{tabular}


Cotillo z., L. G. - Tentativas đa inhibición de la síntesis de enterotoxina estafilocóccica por peniclina y estreptomicina. Rev. Saúde públ., S. Paulo, 1(2):188-192, dez. 1967.

A pesar de la presencia de formas pleomorficas y protoplastos en todas las concentraciones de penicilina superior a 200 unidades por $\mathrm{ml}$ de medio de cultivo, no fué posible constatar ausencía de enterotoxina A o B en las cepas empleadas en esta investigación. Todas ellas presentavam a las 48 horas reacción de immunodifusión en gel positiva cuando colocadas frente a los sueros específicos.

En la Tabla 2 estan consignados los resultados obtenidos al emplear la estreptomicina en las tentativas de inhibir la síntesis de las enterotoxinas estafilocóccicas. La estreptomicina ocasiona um pleomorfismo mas acentuado en los estafilococos sometidos a su acción que la que se presenta cuando se utiliza la penicilina.

Como se puede ver en la Tabla 2, las pequeñas concentraciones de estreptomicina $(10-50-100 \mu \mathrm{g} / \mathrm{ml})$ no impiden la sín tesis de enterotoxinas Sim embargo, las concentraciones mas altas ya no permitem la formación de las proteinas enterotóxicas de estos estafilococos. Esta inhibición es completa a partir de la concentración de $1000 \mu \mathrm{g}$ de estreptomicina por $\mathrm{ml}$ de medio de cultivo.

\section{I SCUS I ON}

Cuando habíamos terminado la parte experimental de este trabajo tuvimos notícia de dos notas preliminares publicadas en los Estados Unidos referentes a inhibición de la formación de enterotoxina estafilococcica $B$ en cultivos en caldo (Friedman $\left.{ }^{8}, 1966\right)$ y a la inhibición de la elaboración de proteínas estafilocóccicas enterotóxicas por la estreptomicina (Rosenwald \& Lincoln ${ }^{15}, 1966$ ).

Estos dos trabajos traen las observaciones de la inhibición de síntesis de enterotoxina ocasionada por la estreptomicina.

En nuestro trabajo, también la estreptomicina impidió la formación de proteina enterotóxica como puede ser observado en la Tabla 2, lo mismo no sucediendo cuando usamos la penicilina con esta finalidad.

Desde que la penicilina no impide la formación de enterotoxina parece que esta no está relacionada con la pared celular a pesar da las observaciones de Friedman $\&$ White $^{9}(1965)$.

T A B L A 2

Inhibición de la sintesis de enterotoxinas estabilocóccicas por la estreptomicina

\begin{tabular}{|c|c|c|c|c|c|c|c|c|c|}
\hline \multirow{2}{*}{$\begin{array}{l}\text { Concentracio- } \\
\text { nes de estdep- } \\
\text { micina }\end{array}$} & \multirow{2}{*}{ 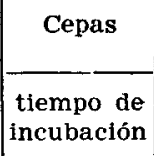 } & \multicolumn{2}{|c|}{ ATCC 13565} & \multicolumn{2}{|c|}{ ATCC 14458} & \multicolumn{2}{|c|}{ S 6} & \multicolumn{2}{|c|}{ S 100} \\
\hline & & $48 \mathrm{~h}$ & $72 \mathrm{~h}$ & $48 \mathrm{~h}$ & $72 \mathrm{~h}$ & $48 \mathrm{~h}$ & $72 \mathrm{~h}$ & $48 \mathrm{~h}$ & $72 \mathrm{~h}$ \\
\hline $10 \mathrm{~g} / \mathrm{ml}$ & & + & + & + & + & + & + & + & + \\
\hline $50 \mathrm{~g} / \mathrm{ml}$ & & + & + & + & + & + & + & + & + \\
\hline $100 \mathrm{~g} / \mathrm{ml}$ & & + & + & + & + & + & + & + & + \\
\hline $500 \mathrm{~g} / \mathrm{ml}$ & & - & - & - & + & + & + & - & + \\
\hline $1.000 \mathrm{~g} / \mathrm{ml}$ & & - & - & - & - & - & - & - & - \\
\hline $2.000 \mathrm{~g} / \mathrm{ml}$ & & - & - & - & - & - & - & - & - \\
\hline $4.000 \mathrm{~g} / \mathrm{ml}$ & & - & - & - & - & - & - & - & - \\
\hline
\end{tabular}

$+=$ presencia de enterotoxinas $\mathrm{A} \circ \mathrm{B}$

- = ausencia de enterotoxinas A O B 
COTILlo Z., L. G. - Tentativas da inhibición de la síntesis de enterotoxina estafilocóccica por penicilina y estreptomicina. Rev. Saúde públ., S. Paulo, 1(2):188-192, dez. 1967.

- Por otra parte, la acción de la estreptomicina al impedir la producción de enterotoxina pareceria indicar que esta se procesa a nivel citoplasmático, de donde sería expelida para el exterior y al pasar a través de la pared celular la contaminaria, ofreciendo asi el aspecto de proteína enterotóxica ligada a la pared celular como fué observado por Friedman \& White ${ }^{8}$ (1965).

\section{CON CLUSIOES}

La penicilina usada en diversas concentraciones provoca el aparecimiento de formas pleomórficas y protoplastos en cultivos de estafilococos sin impedir la síntesis de las proteínas enterotóxicas.

La estreptomicina a partir de $500 \mu \mathrm{g}$ por $\mathrm{ml}$ de medio de cultivo, impide totalmente la formación de las proteinas enterotóxicas en casi todas las cepas utilizadas.

Parece que la síntesis de la enterotoxina estafilocóccica se procesa a nivel del citoplasma celular.

\section{S U M M A R Y}

An attempt to inhibit Staphyloccoci enterotoxin production of strains ATCC 13565, ATCC 14458, S6 and S100 was made with penicillin and streptomycin. Results suggest that penicillin does not prevent enterotoxic protein synthesis, while streptomycin, in doses of $500 \mu \mathrm{g} / \mathrm{ml}$ prevent it in almost all strains. With doses of $1.000 \mu \mathrm{g} / \mathrm{ml}$ the presence of enterotoxin was not detected in any of the strains under study. Possible explanations for such results are suggested in this paper.

\section{REFERENCIAS BIBLIOGRAFICAS}

1. CASMAN, E. P. - Serologic studies of staphylococcal enterotoxin. Publ. Hlth Reps., Wash., 73 (7):599-609, July 1958.
2. CASMAN, E. P. \& BENNETT, R. W. Culture medium for the production of staphylococcal enterotoxin A. $J$. Bact., 86(1):18-23, July 1963.

3. COTILlO,Z., L. - Las formas L. Suinterpretación a la luz de la microblologia moderna. Lima, 1962. (Tesis de Bachiller - Facultad de Farmacia y Bioquimica - Universidad de San Marcos de Lima-Perú).

4. CROWLE, A. S. - A simplified micro double diffusion agar precipitation technique. J. Lab. clin. Med., 52 (5) :784-787, Nov. 1958.

5. DACK et alii - Prevent med., 4:167-75, 1930. Apud DACK, G. M. Food poisoning. 3 th ed. Chicago, Univ. Chicago Press, 1956.

6. DIENES, L. \& SHARP, J. - The role of high electrolyte concentration in the production and growth of $L$ forms of bacteria. J. Bact., $71: 208-213$, 1956.

7. DOLMAN, C. E. et alii - Canadian publ. $H \neq h J ., 27: 489,1963$. Apud. HAMMON, W. $\mathrm{McD}^{12}$.

8. FRIEDMAN, M. E. - Inhibition of staphylococcal enterotoxin $B$ formation in broth cultures. J. Bact., 92(1): 277-278, July 1966.

9. FRIEDMAN, M. E. \& WHITE, J. D. Immunofluorescent demonstration of cell associated staphylococcal enterotoxin B. J. Bact., $89(4): 1153$, Apr. 1965.

10. HALLANDER, $\mathrm{H}$. O. - Production of large quantities of enterotoxin $B$ and other staphylococcal toxins on solid media. Acta path. microbiol. scand., 63(2): 299-305, 1965.

11. HARTMAN \& GOODGAL - Rev. Microbiol, 13:463, 1959. Apud FRIEDMAN \& WHITE 8 .

12. HAMMON, W. MeD. - Staphylococeus enterotoxin an improved cat test, chemical and immunological studies. A mer. J. publ. Hlth, 31(11):1191-1198, Nov. 1941.

13. KLIENEBERGER-NOBEL, E. - Filterable forms of bacteria. Bact. Rev., 15 (2):77-103, June 1951.

14. MARSTON, J. - Observation on L forms of staphylococci. J. infect. Dis., 108: 75-84, 1961.

15. ROSENWALD, A. J. \& LINCOLN, R. E. - Streptomycin inhibition of elaboration of staphylococcal enterotoxic protein. J. Bact., 92(1):279-280, July 1966. 